Economics Development Analysis Journal 6(2)(2017) Economics Development Analysis Journal

\title{
Analisis Faktor-Faktor yang Mempengaruhi PMDN di Jawa Tengah
}

\author{
Ferdila Dedy Utomo ${ }^{\bowtie}$
}

Jurusan Ekonomi Pembangunan, Fakultas Ekonomi, Universitas Negeri Semarang

\begin{tabular}{|c|c|}
\hline Info Artikel & Abstrak \\
\hline $\begin{array}{l}\text { Sejarah Artikel: } \\
\text { Diterima Januari } 2017 \\
\text { Disetujui Maret } 2017 \\
\text { Dipublikasikan Mei } 2017 \\
\text { Keywords: } \\
\text { Domestic investments, } \\
\text { Regression, Interest Rates, } \\
\text { Labor, Government }\end{array}$ & $\begin{array}{l}\text { Penelitian ini bertujuan untuk: menganalisis pengaruh suku bunga kredit, pengeluaran pemerintah } \\
\text { dan tenaga kerja terhadap Penanaman Modal Dalam Negeri (PMDN) di Jawa Tengah. Jenis } \\
\text { penelitian ini adalah kuantitatif, data yang digunakan dalam penelitian ini adalah data sekunder } \\
\text { runtut waktu (time series) dengan periode } 28 \text { tahun dimulai pada tahun } 1988 \text { sampai tahun } 2015 \text {. } \\
\text { Metode analisis yang digunakan adalah Ordinary Least Square (OLS). Pengujian menggunakan uji t- } \\
\text { statistik dan uji F-statistik. Hasil penelitian ini menunjukkan bahwa variabel pengeluaran } \\
\text { pemerintah berpengaruh negatif dan tidak signifikan terhadap PMDN. Variabel tenaga kerja } \\
\text { berpengaruh positif dan signifikan terhadap PMDN. Sedangkan variabel suku bunga kredit } \\
\text { berpengaruh negatif tetapi tidak signifikan terhadap PMDN. }\end{array}$ \\
\hline
\end{tabular}

Spending

\begin{abstract}
The objectives of this research are to analyze the effect of lending interest rate, government expenditure and labor on domestic investments in Central Java. This research is a quantitative study in which the data used as the reference is secondary time series based data with a period of 28 years from the beginning in 1988 until 2015. The analytical method applied is Ordinary Least Square (OLS) while the statistical assessment was using t-test and F-test statistics. Based on the results of data analysis, it is showed that the variable government expenditure has a negative and not significant effect on domestic investment. The variable labor growth has a positive and significant effect on domestic investment. The variable lending interest rate has negative effect but not significant on domestic investment.
\end{abstract}

\footnotetext{
Alamat korespondensi:

Gedung L2 Lantai 2 FE Unnes

Kampus Sekaran, Gunungpati, Semarang, 50229

E-mail: ferdila.du@gmail.com
}

ISSN 2252-6765 


\section{PENDAHULUAN}

Sejak pemerintahan Presiden Joko Widodo pemerintah sudah mengeluarkan 10 kali paket kebijakan ekonomi. Paket kebijakan ekonomi tahap I sampai tahap VIII dikeluarkan pada tahun 2015 dan sisanya pada tahun 2016. Paket tersebut ditujukan sebagai alat untuk memperkuat ekonomi di tengah pengaruh ekonomi global dan pelambatan ekonomi dalam negeri sebagai dampaknya. Efek dari investasi dan penanaman modal dalam negeri bergantung pada kebijakan makroekonomi di negara tersebut (Furceri, et al, 2012).

Salah satu paket kebijakan tersebut dimaksudkan untuk meningkatkan investasi tepatnya dalam paket kebijakan ekonomi tahap II yang dikeluarkan pada tanggal 29 September 2015. Isinya yaitu berupa deregulasi dan debirokratisasi peraturan untuk mempermudah investasi baik investasi dalam negeri (PMDN) maupun investasi asing (PMA). Untuk menarik penanaman modal, terobosan kebijakan yang ditetapkan yaitu memberikan layanan cepat dalam bentuk pemberian izin investasi dalam waktu 3 jam di Kawasan Industri. Dengan mendapatkan izin tersebut investor sudah bisa langsung melakukan kegiatan investasi. Untuk menstimulus pertumbuhan ekonomi salah satunya dengan memfasilitasi investasi sehingga dapat berperan dalam meningkatkan efisiensi ekonomi (Harada, 2015).

Pemerintah sadar akan pentingnya investasi bagi pertumbuhan ekonomi. Investasi dan pertumbuhan ekonomi memiliki hubungan yang positif (Lamsiraroj, 2016). Investasi merupakan salah satu komponen dari output nasional atau PDB, jadi investasi mempengaruhi pertumbuhan ekonomi. Sebagai negara berkembang Indonesia memang butuh modal yang besar untuk mengejar ketertinggalan ekonomi. Berikut perkembangan realisasi PMDN Provinsi di Jawa:

Tabel 1. Perkembangan Realisasi PMDN Provinsi di Jawa Tahun 2010-2015 (Miliar Rupiah)

\begin{tabular}{llllllll}
\hline TAHUN & $\begin{array}{l}\text { Proyek } \\
\text { Investasi }\end{array}$ & $\begin{array}{l}\text { DKI } \\
\text { Jakarta }\end{array}$ & Jawa Barat & $\begin{array}{l}\text { Jawa } \\
\text { Tengah }\end{array}$ & $\begin{array}{l}\text { D.I } \\
\text { Yogyakarta }\end{array}$ & $\begin{array}{l}\text { Jawa } \\
\text { Timur }\end{array}$ & Banten \\
\hline 2010 & P & 86 & 103 & 40 & 3 & 89 & 76 \\
& I & $4,598.5$ & $15,799.8$ & 795.4 & 10 & $8,084.1$ & $5,852.5$ \\
2011 & P & 84 & 170 & 100 & 7 & 157 & 83 \\
& I & $9,256.4$ & $11,194.3$ & $2,737.8$ & 1.6 & $9,687.5$ & $4,298.6$ \\
2012 & P & 72 & 125 & 78 & 6 & 289 & 66 \\
& I & $8,540.1$ & 11,384 & $5,797.1$ & 334 & $21,520.3$ & $5,117.5$ \\
2013 & P & 156 & 232 & 145 & 15 & 437 & 100 \\
& I & $5,754.5$ & $9,006.1$ & $12,593.6$ & 283.8 & $34,848.9$ & $4,008.7$ \\
2014 & P & 118 & 258 & 121 & 14 & 303 & 100 \\
& I & $17,811.4$ & $18,726.9$ & $13,601.6$ & 703.9 & 38,132 & $8,081.3$ \\
& P & 171 & 383 & 186 & 23 & 217 & 185 \\
& I & $15,512.7$ & $26,272.8$ & $15,410.7$ & 362.4 & $35,489.7$ & $10,709.9$ \\
\hline
\end{tabular}

Sumber: bkpm.co.id

Berdasarkan tabel 1. dapat diketahui bahwa nilai PMDN Jawa Tengah nilainya terus meningkat dari tahun 2010 sampai tahun 2015. Nilai PMDN Jawa Tengah pada tahun 2010 nilainya hanya 795,4 miliar rupiah. Ini membuat Jawa Tengah berada pada peringkat ke-2 dengan nilai PMDN paling sedikit setelah D.I Yogyakarta di Jawa. Nilai PMDN tersebut terbilang sedikit jika dibandingkan dengan provinsi-provinsi lainnya selain D.I Yogyakarta, nilai PMDN DKI Jakarta sebesar 4.598,5 miliar rupiah, Jawa Barat 15.799,8 miliar rupiah, Jawa 
Timur 8.084,1 miliar rupiah dan Banten sebesar 5.852,5 miliar rupiah. Pada tahun 2011 nilai PMDN Jawa Tengah meningkat menjadi sebesar 2.737,8 miliar rupiah namun nilainya masih lebih kecil ketimbang provinsi lainnya selain D.I Yogyakarta. Pada tahun 2013 nilai PMDN Jawa Tengah sebesar 12.593,6 miliar rupiah, hal ini membuat perolehan PMDN Jawa Tengah dapat menyaingi perolehan PMDN Banten dan Jawa Barat. Pada tahun 2012, 2014 dan 2015 nilai PMDN Jawa Tengah dapat menyaingi nilai PMDN Banten dan jika diurutkan maka perolehan PMDN Jawa Tengah menempati urutan ke-4 terbesar di Jawa.

Nilai PMDN Jawa Tengah dalam kurun waktu 5 tahun terakhir mengalami tren yang meningkat, namun nilai tersebut jika dibandingkan dengan provinsi-provinsi lain di Jawa nilai tersebut sedikit kurang bisa bersaing. Nilai total investasi Jawa Tengah menduduku peringkat ke-4 di Jawa dari segi banyaknya nilai investasi. Padahal jumlah tenaga kerja di Jawa Tengah merupakan yang terbesar ketiga di Jawa dan dalam beberapa tahun terakhir jumlahnya terus mengalami peningkatan.

\section{METODE PENELITIAN}

Data yang digunakan dalam penelitian ini merupakan data sekunder yang berbentuk data time series atau runtut waktu. Data yang diteliti meliputi data suku bunga kredit, pengeluaran pemerintah dan tenaga kerja. Periode dari data

yang digunakan yaitu dari tahun 1988-2015. Variabel penelitian dalam penelitian ini yaitu Penanaman Modal Dalam Negeri (PMDN) Jawa Tengah sebagai variabel dependent, suku bunga kredit, tenaga kerja Jawa Tengah dan pengeluaran pemerintah Jawa Tengah sebagai variabel independentnya. Data populasi yang diambil dalam penelitian ini dalam rentang tahun 1988 sampai tahun 2015. Untuk mengetahui seberapa besar factor-faktor yang mempengaruhi investasi di Jawa Tengah selama kurung waktu 1988-2015 digunakan metode OLS (Ordinary Least Square). Dalam pengolahan data menggunakan alat bantu software eviews 6 .

Secara ekonometrika hubungan antara suku bunga kredit, pengeluaran pemerintah dan tenaga kerja terhadap Penanaman Modal Dalam Negeri (PMDN) Jawa Tengah dapat dianalisis dengan menggunakan persamaan sebagai berikut:

$\mathrm{PMDN}_{\mathrm{t}}=\alpha_{\mathrm{t}}+\beta_{1} \mathrm{SBK}_{1 \mathrm{t}}+\beta_{2} \mathrm{TK}_{2 \mathrm{t}}+\beta_{3} \mathrm{PP}_{3 \mathrm{t}}+e_{\mathrm{t}}$

\author{
Dimana: \\ $\mathrm{PMDN}_{\mathrm{t}}$ :Penanaman Modal Dalam Negeri \\ $\mathrm{SBK}_{\mathrm{t}}$ : Suku bunga kredit (persen) \\ $\mathrm{TK}_{\mathrm{t}}$ : Jumlah tenaga kerja \\ PP : Pengeluaran pemerintah \\ e : residual \\ $t \quad$ : Time series
}

\title{
HASIL DAN PEMBAHASAN
}

Hasil Regresi

Tabel 2. Hasil Regresi

\begin{tabular}{lcccc}
\hline Variable & Coefficient & Std. Error & t-Statistic & Prob. \\
\hline LNPP & -1.041809 & 0.655022 & -1.590495 & 0.1248 \\
SBK & -0.015357 & 0.117860 & -0.130301 & 0.8974 \\
LNTK & 28.38936 & 10.56336 & 2.687532 & 0.0129 \\
C & -258.6239 & 99.46459 & -2.600160 & 0.0157 \\
R-squared & 0.556233 & Mean dependent var & 13.17481 \\
Adjusted R-squared & 0.500762 & S.D. dependent var & 1.880479 \\
S.E. of regression & 1.328686 & Akaike info criterion & 3.537821 \\
Sum squared resid & 42.36973 & Schwarz criterion & 3.728136 \\
Log likelihood & -45.52949 & Hannan-Quinn criter. & 3.596002 \\
\hline
\end{tabular}


Ferdila Dedy Utomo / Economics Development Analysis Journal 6 (2) (2017)

\begin{tabular}{llll}
\hline F-statistic & 10.02748 & Durbin-Watson stat & 1.233145 \\
Prob(F-statistic) & 0.000181 & & \\
\hline
\end{tabular}

Sumber : Lampiran, olah data E-views

Dari hasil regresi table 4.7 dapat diperoleh persamaan sebagai berikut :

$\mathrm{PMDN}=-258.6239+-0.015357 \mathrm{SBK}+$ 28.38936LNTK + -1.041809LNPP $+e$

\section{Uji Signifikansi Parameter Individual (Uji t)}

Uji t-statistik digunakan untuk mengetahui pengaruh masing-masing variabel independen terhadap variabel dependen secara parsial. Berdasarkan Tabel 4.6 diketahui bahwa t-statistik variabel suku bunga kredit (SBK) sebesar -0.130301 dengan probabilitas 0.8974 yang artinya pada tingkat keyakinan $\alpha=1 \%, 5 \%$ dan $10 \%$ nilai suku bunga kredit tidak memiliki hubungan yang signifikan terhadap PMDN.

Variabel tenaga kerja (LNTK) memiliki tstatistik sebesar 2.687532 dengan probabilitas 0.0129 yang artinya variabel tenaga kerja memiliki hubungan positif dan signifikan terhadap PMDN pada alfa 5\%.

Variabel pengeluaran pemerintah (LNPP) memiliki t-statistik sebesar ---1.590495 dengan probabilitas 0.1248 tidak signifikan pada alfa berapapun. Artinya pengeluaran pemerintah memiliki hubungan negarif dan tidak signifikan terhadap PMDN.

\section{Uji Signifikansi Bersama-sama (Uji F)}

Uji F-statistik digunakan untuk mengetahui ada atau tidaknya pengaruh variabel independen secara bersama-sama yaitu suku bunga kredit (SBK), tenaga kerja (TK) dan pengeluaran pemerintah (PP) terhadap variabel dependen penanaman modal dalam negeri (PMDN). Berdasarkan hasil regresi dari pengaruh suku bunga kredit, tenaga kerja dan pengeluaran pemerintah terhadap PMDN Jawa Tengah dalam tabel 4.6 diperoleh probabilitas Fstatistik sebesar 0.000181 signigikan pada alfa $1 \%$ dan 5\%. Artinya variabel independen pengeluaran pemerintah, tenaga kerja dan suku bunga kredit secara bersama-sama berpengaruh secara signifikan terhadap variabel dependen PMDN Jawa Tengah.

\section{Koefisiensi Determinasi $\left(\mathbf{R}^{2}\right)$}

Koefisien determinasi $\left(\mathrm{R}^{2}\right)$ digunakan untuk mengukur seberapa jauh kemampuan model dalam menerangkan himpunan variasi variabel dependen. Nilai dari koefisien determinasi adalah antara 0 (nol) sampai 1 (satu). Nilai $\mathrm{R}^{2}$ yang kecil menunjukkan kemampuan variabel-variabel independen dalam menjelaskan variasi variabel dependen amat terbatas. Sebaliknya apabila nilai $\mathrm{R}^{2}$ mendekati satu berarti variabel-variabel independen memberikan hampir semua informasi yang dibutuhkan untuk memprediksi variasi variabel dependen.

Hasil regresi dari pengaruh suku bunga kredit, tenaga kerja dan pengeluaran pemerintah terhadap PMDN Jawa Tengah dalam tabel 4.6 diperoleh nilai $\mathrm{R}^{2}$ sebesar 0.556233 . Hal ini berarti 55,62\% variasi PMDN Jawa Tengah mampu dijelaskan oleh himpunan variasi variabel independen suku bunga kredit, tenaga kerja dan pengeluaran pemerintah. Sedangkan sisanya $44,38 \%$ dijelaskan oleh variabel-variabel lain diluar model.

\section{Pengaruh Tenaga Kerja Terhadap PMDN}

Berdasarkan hasil analisis didapatkan bahwa variabel tenaga kerja berpengaruh positif dan signifikan dengan koefisien positif sebesar 28.38936 terhadap PMDN Jawa Tengah. Pertumbuhan tenaga kerja memiliki pengaruh yang signifikan terhadap nilai PMDN. Artinya jika terjadi peningkatan jumlah tenaga kerja sebesar satu jiwa maka nilai PMDN Jawa Tengah akan mengalami peningkatan sebesar 28,39 rupiah.

\section{Pengaruh Pengeluaran Pemerintah Terhadap PMDN}

Berdasarkan hasil analisis regresi didapatkan bahwa variabel pengeluaran pemerintah berpengaruh negatif dan tidak signifikan terhadap PMDN Jawa Tengah dengan koefisien sebesar -1.041809. Hasil ini tidak sesuai teori dan tidak signifikan pula. 
Pengeluaran pemerintah mendapatkan peran sebagai pendorong/stimulus bagi kegiatan perekonomian di suatu daerah dimana pengeluaran pemerintah memberi dukungan terhadap sektor swasta dalam meningkatkan perekonomian daerah terutama untuk meningkatkan investai.

Pengaruh Suku Bunga Kredit Terhadap PMDN

Berdasarkan hasil analisis regresi didapatkan bahwa variabel suku bunga kredit berpengaruh negatif dan tidak signifikan terhadap PMDN Jawa Tengah dengan koefisien sebesar -0.015357 . Hasil ini sesuai dengan teori namun tidak signifikan.

\section{SIMPULAN}

Penelitian ini dimaksudkan untuk mengkaji pengaruh variabel, suku bunga kredit, tenaga kerja dan pengeluaran pemerintah terhadap PMDN Jawa Tengah tahun 1988 2015. Berdasarkan hasil analisis data yang telah dilakukan maka kesimpulannya adalah (1) Variabel SBK mempunyai pengaruh negatif namun tidak signifikan terhadap PMDN Jawa Tengah, (2) Variabel tenaga kerja mempunyai pengaruh positif dan signifikan terhadap PMDN Jawa Tengah. Apabila tenaga kerja meningkat maka PMDN akan meningkat, (3) Variabel pengeluaran pemerintah mempunyai pengaruh negatif dan tidak signifikan mempengaruhi PMDN Jawa Tengah.

\section{DAFTAR PUSTAKA}

Adam, August. 2014. Analisis Penanaman Modal Asing di Indonesia. Sekolah Tinggi Ilmu Statistik (STIS) Jakarta.

Ajija, Shochrul Rohmatul, Sari, Dyah Wulan, Setianto, Rahmat Heru dan Primanti, Martha Ranggi. 2011. Cara Cerdaas Menguasai Eviews. Salemba Empat, Jakarta.

Anwar, Sanusi. 2011. Metode Penelitian Bisnis. Salemba Empat, Jakarta.

Dliaulhaq, Muhammad. 2011. Analisis Pengaruh Suku Bunga Kredit, Tenaga Kerja dan Tingat Inflasi Terhadap Penanaman Modal Dalam Negeri (PMDN) Di Jawa Tengah Tahun 1988-2009. Universitas Negeri Semarang :Fakultas Ekonomi, skripsi.
Febriananda, Fajar. 2011. Analisis Faktor-Faktor Yang Mempengaruhi Investasi Dalam Negeri di Indonesia. Universitas Diponegoro : Fakultas Ekonomi dan Bisini, skripsi.

Furceri, Davide, et al. 2012. The Effect of Episodes of Large Capital Inflows on Domestic Credit. The North American Journal of Economics and Finance, Volume 23, Pages 325-344.

Gujarati, Damodar dan Porter, C. Dawn. 2010. Dasar-dasar Ekonometrika. Salemba empat, Jakarta.

Harada, Tsutomu. 2015. Structural Change and Economic Growth with Relation Specific Investment. Structural Change and Economic Dynamics, Volume 32, Pages 1-10.

Kuncoro, Mudrajad. 2004. Ekonomi Pembangunan, Teori, Masalah dan Kebijakan.Erlangga, Yogyakarta

Lamsiraroj, Sasi. 2016. The Foreign Direct Investment Economic Growth Nexus. International Review of Economics and Finance, Volume 42, Pages 116-133.

Nopirin. 2010. Ekonomi Moneter. BPFE UGM, Yogyakarta.

Prasetya, Ferry. 2012. Modul Ekonomi Publik. Universitas Brawijaya

Prasetyo, P. Eko. 2009. Fundamental Makro Ekonomi. Beta Offset, Yogyakarta.

Prihatiningsih, Estu dan Wantara, Ign. Agus. Analisis Pengaruh Produk Domestik Bruto, Suku Bunga, dan Pengeluaran Pemerintah Terhadap Investasi di Indonesia Tahun 1992 2012. Universitas Atma Jaya Yogyakarta : Fakultas Ekonomomi.

Samuelson, Paul A. dan Nordhaus, William D.2004. Ilmu Makroekonomi.Jakarta: PT. Media Global Edukasi.

Sasana, Hadi, 2008. Analisis Faktor-Faktor Yang Mempengaruhi Investasi Swasta di Jawa Tengah. Jurnal JEJAK 1(1), 1-10

Suharsimi, Arikunto. 2006. Prosedur Penelitian Suatu Pendekatan Praktik. Rineka Cipta, Jakarta.

Sukirno, Sadono. 2010. Teori Pengantar Makroekonomi. Jakarta: PT. Raja Grafindo Persada.

Sumarsono, Sonny. 2003. Ekonomi Sumber Daya Manusia Teori dan Kebijakan Publik. Graha ilmu, Yogyakarta

Wahyuni, Daru. 2004. Perilaku Investasi di Indonesia : Kajian Jangka Pendek dan Jangka Panjang. Jurnal Ekonomi dan Pendidikan 2(1), 59-72. 